\title{
Stability Analysis of Dangerous Rockmass Considering Rainfall and Seismic Activity with a Case Study in China's Three Gorges Area
}

\author{
Jie Hu, Hongliang Liu, Liping Li*, Shen Zhou, Qi Zhang, Shangqu Sun \\ Geotechnical and Structural Engineering Research Center, Shandong University, Jinan, Shandong, China
}

Received: 27 August 2017

Accepted: 22 October 2017

\begin{abstract}
Rainfall and seismic activity have significant influence on the stability of dangerous rockmass. In this paper, the dangerous rockmasses are classified into three instability types according to the failure modes: sliding, falling, and toppling. The discrete element method (COMSOL) was carried out to investigate the stability of three different rockmass types. In the numerical simulation, three load combinations were applied to the numerical model: 1) rockmass weight, 2) rockmass weight + fissure water pressure, and 3) rockmass weight + fissure water pressure + earthquake force. The results show that rainfall and seismic activity play important roles in rockmass stability and the displacement and principal stress of the rockmass are influenced obviously. Wangxia dangerous rockmass in the Great Three Gorges area was selected as a case study, and its stability was analyzed by geological investigation, numerical simulation, and static calculation methods. The results show that there is a high risk that Wangxia dangerous rockmass would lose stability when rainfall season comes and seismic activity happens. A blast was conducted to remove this dangerous rockmass and an SNS net design was proposed to intercept distributed blocks based on rockfall trajectory simulation. The parameters needed in the rockfall simulation program were obtained by laboratory and field tests. Final application proved that the designed treatment is efficient and no damage was caused by the distributed blocks. The whole research may provide a useful reference to similar engineering projects in the future.
\end{abstract}

Keywords: dangerous rockmass, rainfall, seismic activity, Three Gorges, blasting and protection work

\section{Introduction}

The collapse of dangerous rockmass is an emergent geological disaster over the development course of the high-steep rock slope in a mountainous area, particularly under the effect of heavy rainfall and seismic activity [1].

*e-mail: yuliyangfan@163.com
The large falling blocks brought down by the collapse have tremendous kinetic energy, and they are dangerous and could cause a landslide and disrupt traffic routes. Fig. 1 shows some typical disasters caused by such a collapse. To reveal the mechanism and development process of the deformation of dangerous rockmass, a series of studies have been conducted, including geology investigation, field monitoring, theoretical analysis, numerical simulation, and experimental testing [2-6]. 

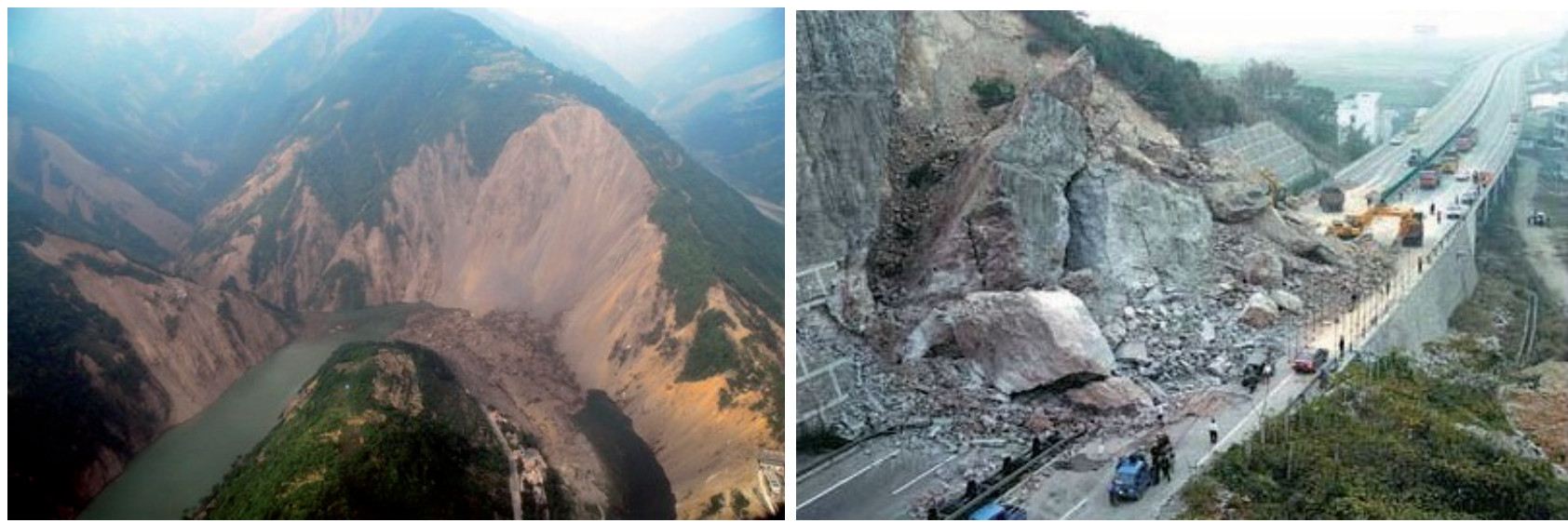

Fig. 1. The traffic routes can be severely damaged by collapse.

In a mountainous area, the collapses of high-steep rock slopes are often triggered by rainstorms, which are mainly caused by seepage pressure or hydrodynamic force. The water flow in the rock fractures can also change physical and mechanical properties of rockmass and lead to the deformation and failure of dangerous rockmass [7]. Huang [8] indicated that the mechanical strength of the structural planes decreases when rainfall is $200-300 \mathrm{~mm} / \mathrm{day}$. Thus, the effect on dangerous rockmass stability caused by rainfall should be considered carefully.

Seismic activity is one of the significant inducements of rockmass collapse and the rock fractures expand quickly under seismic activity [9]. Widely distributed and frequently occurring earthquakes in southwestern China have induced many collapse disasters, which lead to severe damage and heavy casualties. The Wenchuan earthquake $(M S=8.0)$ occurred at 14:28 Beijing standard time on May 12, 2008, near the western edge of the Sichuan Basin in China. Due to its extremely high magnitude, long shaking duration, and the fragile geologic environment in the mountainous area, the Wenchuan earthquake induced severe geological disasters. One of the most significant geologic effects of an earthquake is the triggering of thousands of geohazards over a broad area, including landslides, rockfalls, debris, and dammed lakes [10]. Thus, seismic activity should be considered when analyzing the stability of dangerous rockmass.

Although a lot of studies have been conducted to investigate the stability of dangerous rockmass, little research has considered both rainfall and earthquake factors. In this paper, numerical simulation was carried out to study the effect on three instability types (sliding, falling, toppling) of dangerous rockmass caused by rainfall and seismic activity using COMSOL. Based on field geological investigation, the numerical model of Wangxia dangerous rockmass, which is located in Wushan County in Chongqing, China, was created. The rockmass stability was analyzed and corresponding treatments were proposed to reduce potential collapse risk.

\section{Instability Types of Dangerous Rockmass}

According to the failure mechanism, Chen [11] divided dangerous rockmass into three types: sliding, falling, and toppling (Fig. 2). The sliding dangerous rockmass is defined as one kind of rockmass where there is a penetrated rupture surface existing at the back of dangerous rockmass and its inclination is the same with the slope but lower. The block would slide along a)

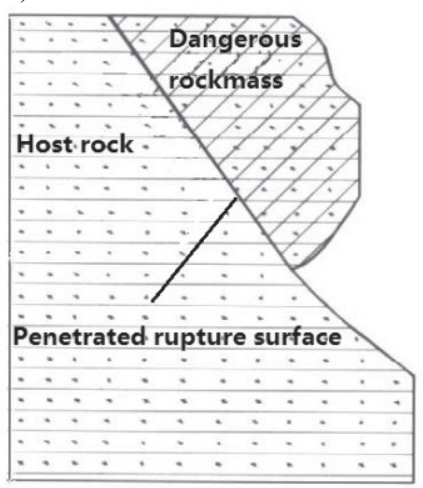

b)

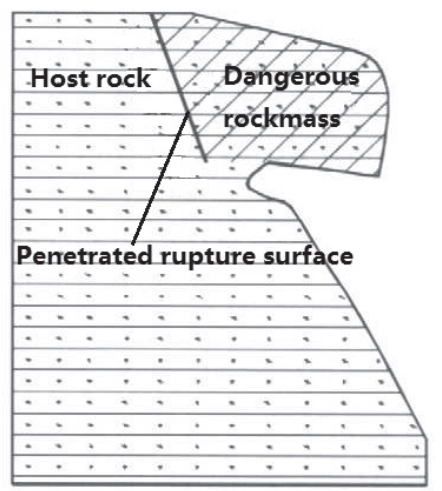

c)

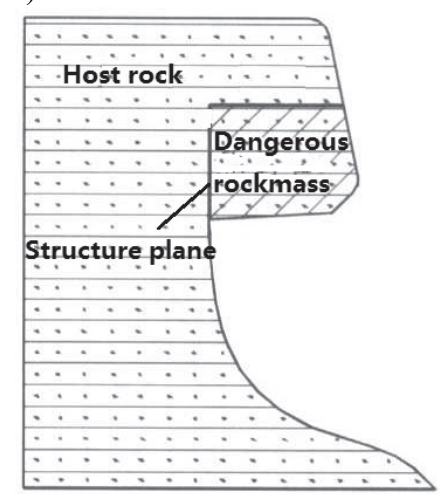

Fig. 2. Three typical dangerous rockmasses: a) sliding type, b) toppling type, c) falling type. 

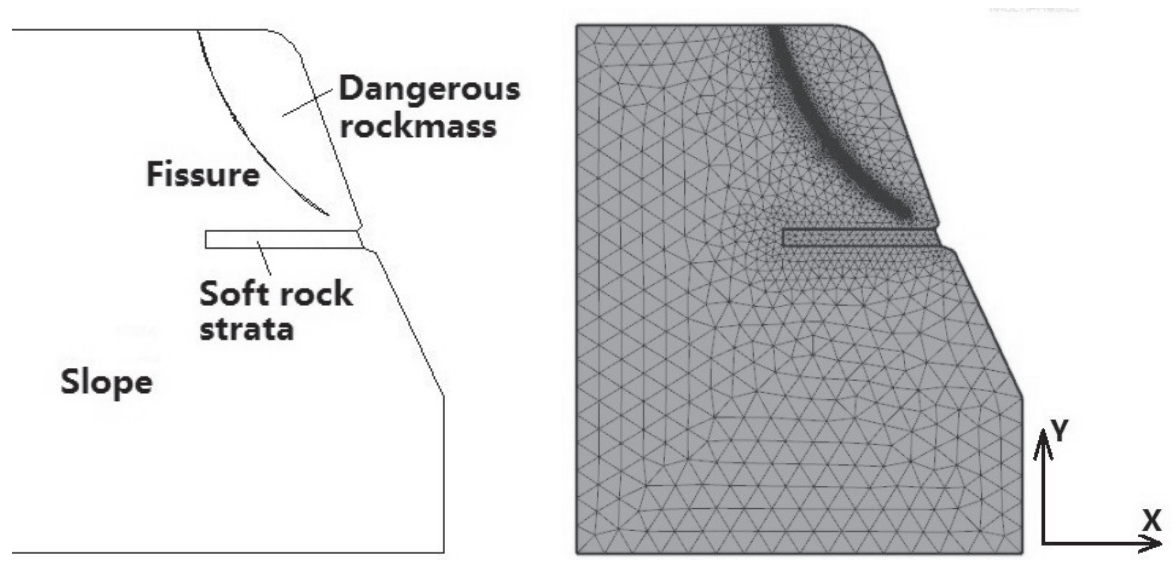

Fig. 3. Numerical model of sliding dangerous rockmass.

the ruptured surface when the dangerous rockmass loses stability, as shown in Fig. 2a). The toppling dangerous rockmass is defined as one kind of rockmass where there is a penetrated steep rupture surface at the back of a dangerous rockmass and there are some free faces at the rockmass bottom. In addition, the gravity center of a dangerous rockmass is always located outside the supporting point of the base rock, as shown in Fig. 2b). The falling dangerous rockmass is defined as one kind of rockmass that the rockmass is cut by structure planes at the bottom and isolated with the host rock, whereas the top of the rockmass is still connected with the host rock. There is no rockmass existing at the bottom of the dangerous rockmass to support it, as shown in Fig. 2c).

\section{Stability Analysis of Dangerous Rockmass Considering Rainfall and Seismic Activity}

In the formation of dangerous rockmass, the internal and external factors are both important to be considered in the analysis of rockmass stability. In this section, the influences of rainfall and seismic activity on the stability of dangerous rockmass are investigated according to the load combinations proposed by Chen et al. [11].

\section{Load Types and Combinations}

The loads causing rock collapse are mainly considered to be of three types: rockmass weight, fissure water pressure, and earthquake force. (1) Rockmass self-gravity can be calculated by the estimated volume and the unitweight. (2) Fissure water pressure mainly considers the hydrostatic pressure and the values are different from if $1 / 3$ fissure height was taken as the waterhead for the natural state and 2/3 fissure height for heavy rainfall state. (3) Earthquake force mainly considers horizontal force and can be calculated by rockmass gravity and horizontal seismic parameter. The point of action is the gravity center of rockmass.

As there is low possibility that the heavy rainfall and earthquake would come at the same time. The load combination was set as follows:

1) Combination 1: rockmass weight + fissure water pressure (natural state).

2) Combination 2: rockmass weight + fissure water pressure (heavy rainfall state).

3) Combination 3: rockmass weight + fissure water pressure (natural state) + earthquake force.

\section{Numerical Analysis of Dangerous Rockmass Stability}

In this section, three models of typical dangerous rockmass were created based on the dangerous rock masses in Xiluodu Hydropower Station in southwestern China [8]. The horizontal displacement and major principal stress of rockmass were analyzed considering aforesaid load combinations using COMSOL. In this simulation, horizontal seismic parameter $(\mu)$ was taken as $0.2 \mathrm{~g}$ and the horizontal earthquake force $(P)$ was calculated as follows:

$$
P=\mu W
$$

...where $W$ is the weight of the dangerous rockmass.

Table 1. Material parameters of the numerical model.

\begin{tabular}{|c|c|c|c|c|c|}
\hline & $\begin{array}{c}\text { Elastic Modulus } \\
(\mathrm{GPa})\end{array}$ & $\begin{array}{c}\text { Poisson } \\
\text { ratio }\end{array}$ & $\begin{array}{c}\text { Cohesion } \\
(\mathrm{MPa})\end{array}$ & $\begin{array}{c}\text { Internal friction } \\
\text { angle }\left({ }^{\circ}\right)\end{array}$ & $\begin{array}{c}\text { Density } \\
\left(\mathrm{kg} / \mathrm{m}^{3}\right)\end{array}$ \\
\hline Slope & 16 & 0.21 & 0.8 & 36 & 2500 \\
\hline Soft rock strata & 9.6 & 0.26 & 0.6 & 28 & 2350 \\
\hline
\end{tabular}


a)

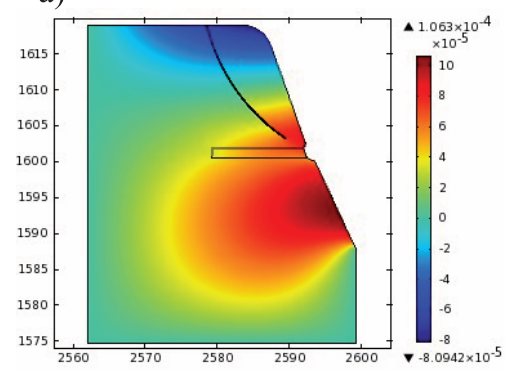

d)

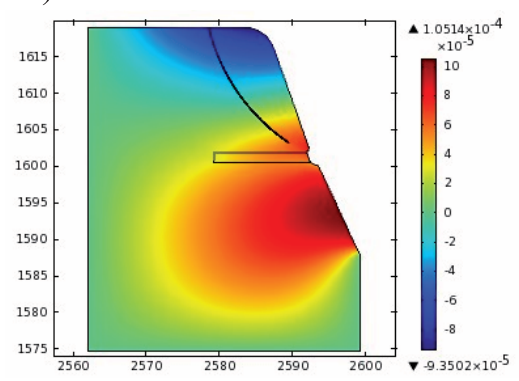

g)

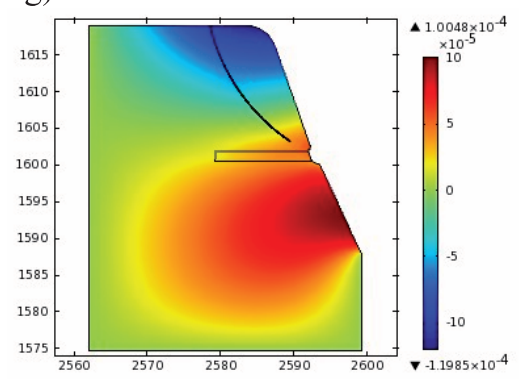

b)

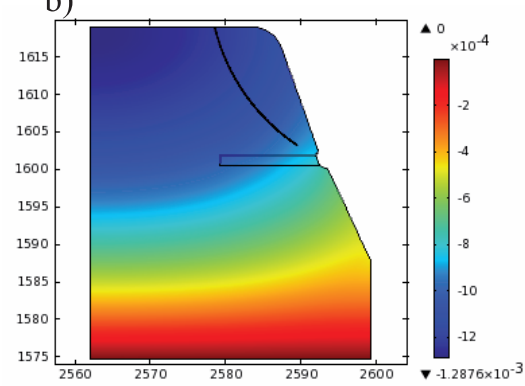

e)

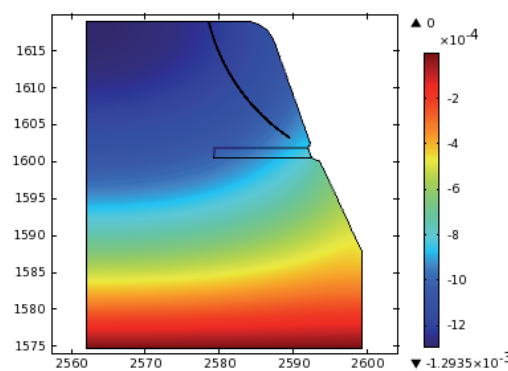

h)

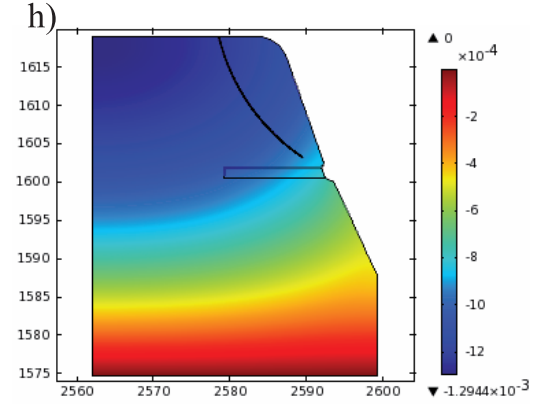

c)

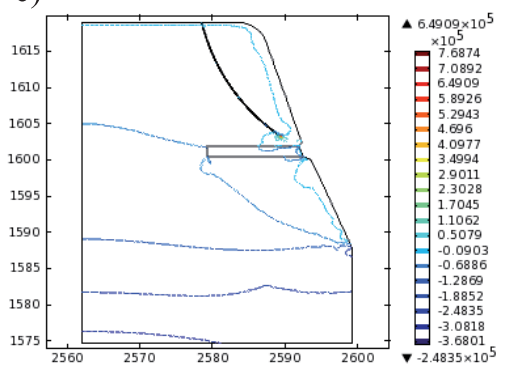

f)

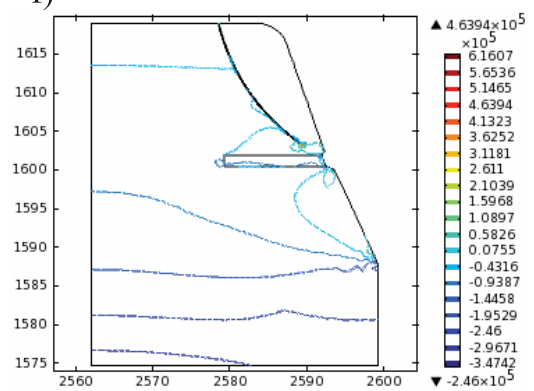

i)

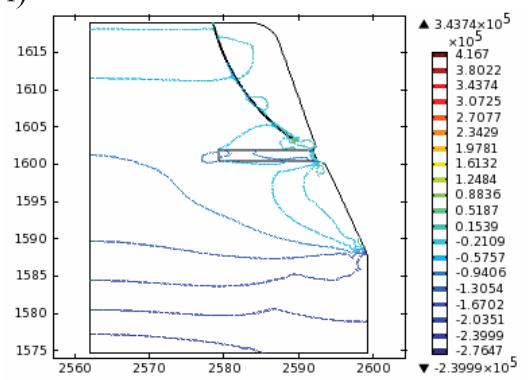

Fig. 4. Displacements in $\mathrm{X}$ and $\mathrm{Y}$ direction and major principal stress of sliding dangerous rockmass considering C1, C2, C3. a) Displacement in X direction (C1), b) Displacement in Y direction (C1), c) Major principal stress (C1), d) Displacement in X direction (C2), e) Displacement in Y direction (C2), f) Major principal stress (C2), g) Displacement in X direction (C3), h) Displacement in Y direction (C3), i) Major principal stress (C3).

\section{Sliding Dangerous Rockmass}

- Rockmass model and material parameters.

The created model is $18 \mathrm{~m}$ in height and $8.7 \mathrm{~m}$ wide. One existing fissure along the slope inclination is about $15 \mathrm{~m}$ long and the average thickness is about $0.1 \mathrm{~m}$. There is a soft rock stratum under the dangerous rockmass and the thickness is about $2 \mathrm{~m}$, which causes the slide action. The numerical model is shown in Fig. 3 and the material parameters are shown in Table 1.

- Numerical analysis of stability of the sliding-type dangerous rockmass.

The displacement in $\mathrm{X}$ and $\mathrm{Y}$ directions and the major principal stress of the numerical model considering the combination $1,2,3(\mathrm{C} 1, \mathrm{C} 2, \mathrm{C} 3)$ are shown in Fig. 4 (a-f), and (g-i), respectively. Observed from the figure, the displacement variations in $\mathrm{Y}$ direction are along the negative axis direction and the displacement values are similar for three different combinations. The displacement value in $\mathrm{Y}$ direction of dangerous rockmass is obviously larger than the displacement of bed rock. As to the displacement value in $\mathrm{X}$ direction, a sudden change happened at the fissure and soft rock stratum. The displacement variations are different in the middle of the slope compared to the upper and lower slope rock. The integral tendency of the slope displacement is that the middle part would be "extruded" by the upper and lower parts. Not the same as the displacement variation tendency, the displacements under $\mathrm{C} 1$ and $\mathrm{C} 2$ are similar and it shows that the rainfall activity does not have evident influence on sliding dangerous rockmass type. Compared to $\mathrm{C} 1$, the displacement value under $\mathrm{C} 2$ is lower, which means that the horizontal earthquake force does not always play a negative role in the stability of dangerous rockmass. For the major principal stress, the stress variation mainly occurred at the fissure tip and the stress direction is similar to the fissure. Compared to the stress mainly caused by dangerous rockmass weight in a natural state, the major principal stress distributions under $\mathrm{C} 2$ and $\mathrm{C} 3$ are mainly caused by fissure water pressure and horizontal earthquake force. We can conclude from it that the main resistance to keep the stability of dangerous rockmass may come from the shear strength of the fissure tip. 

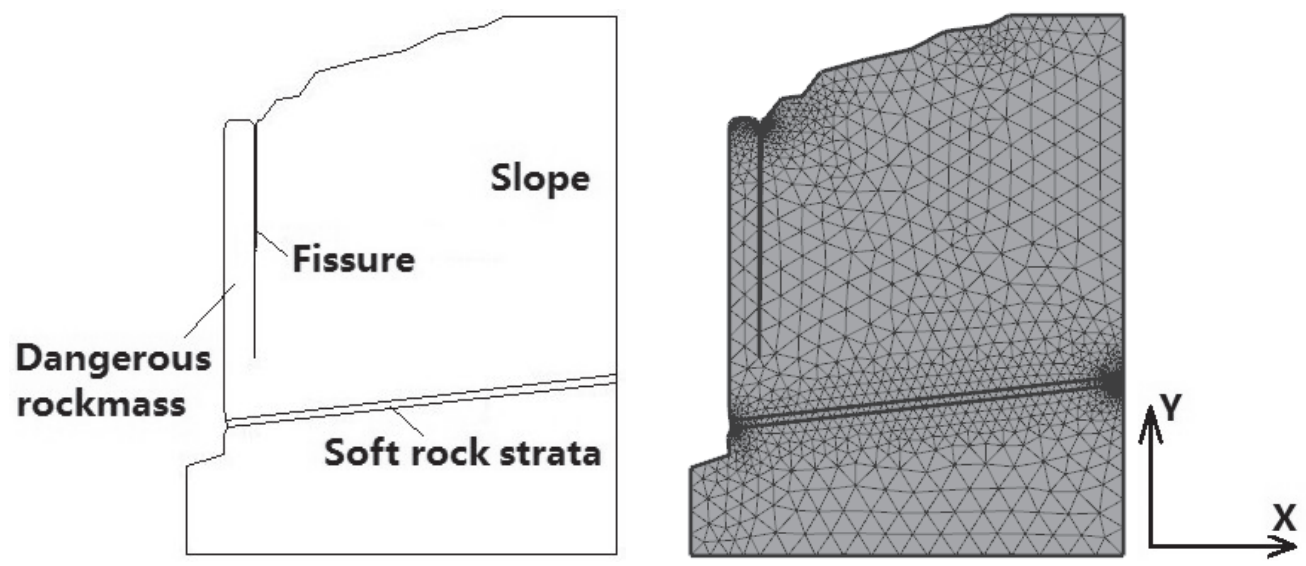

Fig. 5. Numerical model of toppling dangerous rockmass.

\section{Toppling Dangerous Rockmass}

- Rockmass model and material parameters

The created model is $34 \mathrm{~m}$ high and $50 \mathrm{~m}$ wide. One existing vertical fissure near the edge of the rockmass has an extension of $24 \mathrm{~m}$. The thickness at the upper side of this fissure is $0.3 \mathrm{~m}$ and the fissure is closed at the bottom. There is a soft rock stratum under the dangerous rockmass and the thickness is about $1 \mathrm{~m}$. The aforesaid rock structure is the main reason causing the toppling type. The numerical model is shown in Fig. 5 and the material parameters are shown in Table 2.

- Numerical analysis of stability of the toppling-type dangerous rockmass

The displacement in $\mathrm{X}$ and $\mathrm{Y}$ directions and the major principal stress of numerical model considering combinations $1,2,3(\mathrm{C} 1, \mathrm{C} 2, \mathrm{C} 3)$ were shown in Fig. 6 (a-f), and (g-i), respectively. There is an obvious displacement variation of dangerous rockmass under different combinations. The maximum displacements in $\mathrm{X}$ direction of dangerous rockmass under $\mathrm{C} 1, \mathrm{C} 2$, and $\mathrm{C} 3$ are $-1.4269 \mathrm{e}-3 \mathrm{~m},-0.0133 \mathrm{~m}$, and $-0.0168 \mathrm{~m}$, respectively. This shows the displacement has an increase tendency when there are rainfall and seismic activity. We can see the upper rockmass has a major displacement in $\mathrm{X}$ direction than the lower part. Observed from the figure, the displacements in $\mathrm{Y}$ direction are also different under the three different combinations. The outer part of dangerous rockmass has a larger vertical displacement than the inner part, which will accelerate the expansion of the fissure. For the analysis of major principal stress, the stress variation mainly occurred at the fissure tip and we can conclude that the progressive expansion of vertical fissures is the main reason causing the toppling of this dangerous rockmass. When the dangerous rockmass faces rainfall and seismic activity, the fissure has a larger tensile cracking.

\section{Falling Dangerous Rockmass}

- Rockmass model and material parameters

The created model is $34 \mathrm{~m}$ high and $40 \mathrm{~m}$ wide. One existing vertical fissure near the edge of the rockmass has an extension of $24 \mathrm{~m}$ and a thickness of $0.1 \mathrm{~m}$. There is a soft rock stratum under the dangerous rockmass and its thickness is about $0.6 \mathrm{~m}$. The concave rock cavity is the main reason for inducing the falling-type rockmass to collapse. The numerical model is shown in Fig. 7 and the material parameters are shown in Table 3.

- Numerical analysis of stability of the sliding-type dangerous rockmass

The displacement in $\mathrm{X}$ and $\mathrm{Y}$ directions and the major principal stress of numerical model considering combination $1,2,3(\mathrm{C} 1, \mathrm{C} 2, \mathrm{C} 3)$ were shown in Fig. 8(a-f), and (g-i), respectively. As to the displacement in $\mathrm{X}$ and $\mathrm{Y}$ direction of dangerous rockmass, there is an obvious difference under three combinations. The maximum displacement values in $\mathrm{X}$ direction of dangerous rockmass under $\mathrm{C} 1, \mathrm{C} 2$, and $\mathrm{C} 3$ are: $-9.3627 \mathrm{e}-4 \mathrm{~m},-9.2173 \mathrm{e}-3 \mathrm{~m}$, and $-0.0181 \mathrm{~m}$, respectively. This shows that the displacement has an increase tendency when there are rainfall and seismic activity. We can see that the upper side of the rockmass has a larger displacement in $\mathrm{X}$ direction than the lower part. As observed in the figure, the displacement values in $\mathrm{Y}$ direction are also different under the three combinations. The outer part of dangerous rockmass has a vertical displacement along the positive direction of $\mathrm{Y}$ axis,

Table 2. Material parameters of the numerical model.

\begin{tabular}{|c|c|c|c|c|}
\hline & Elastic Modulus (GA) & $\begin{array}{c}\text { Poisson } \\
\text { ratio }\end{array}$ & $\begin{array}{c}\text { Cohesion } \\
(\mathrm{MPa})\end{array}$ & $\begin{array}{c}\text { Internal friction } \\
\text { angle }\left({ }^{\circ}\right)\end{array}$ \\
\hline Slope & 35 & 0.23 & 10 & 45 \\
\hline Soft rock strata & 2.6 & 0.32 & 0.32 & 2600 \\
\hline
\end{tabular}


a)

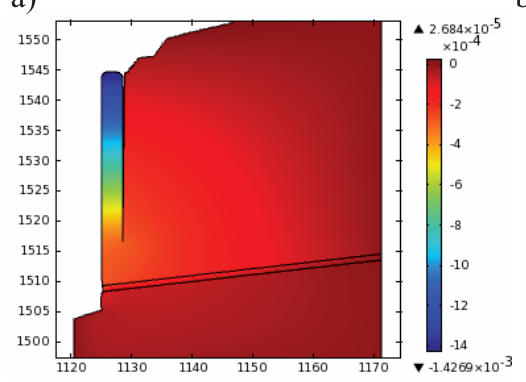

d)

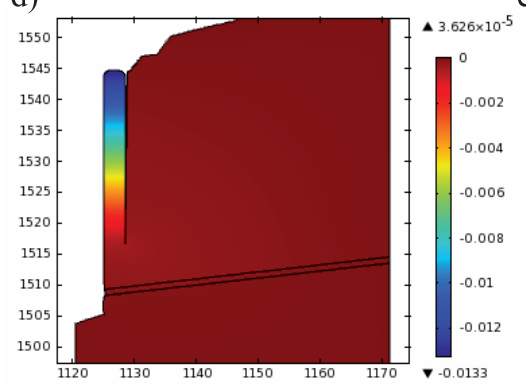

g)

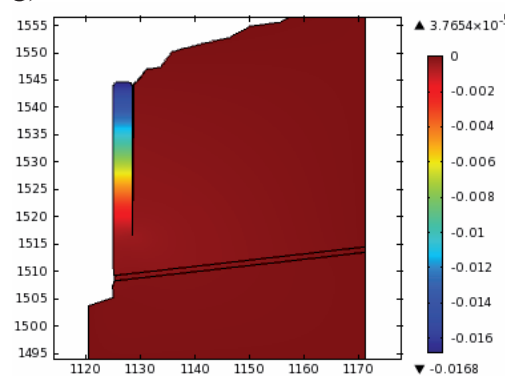

b)

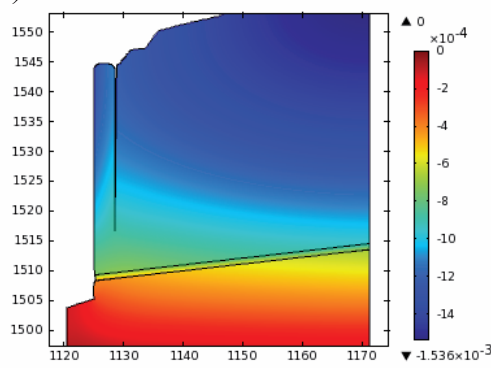

e)

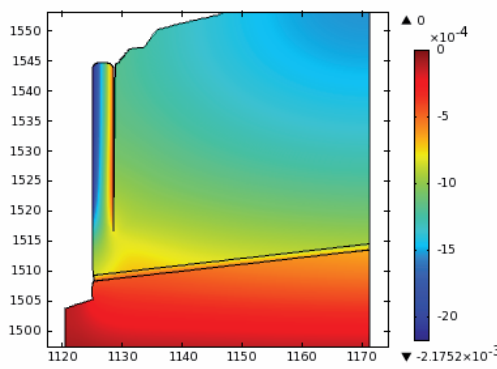

c)

f)
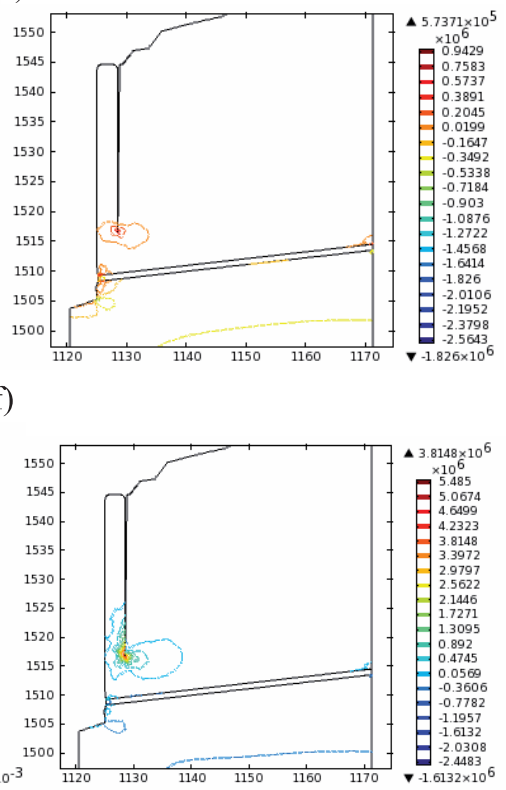

i)

h)

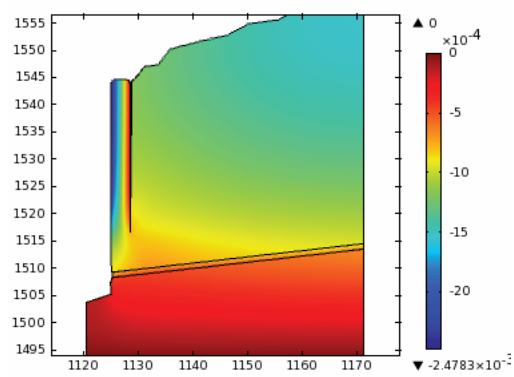

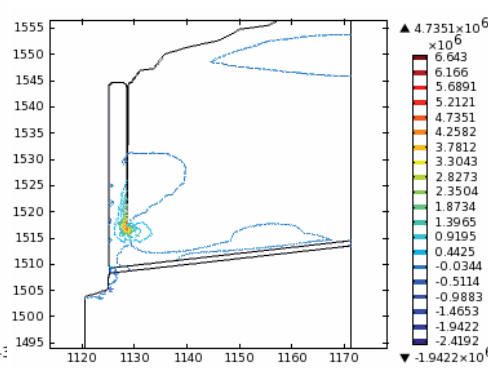

Fig. 6. Displacement in $\mathrm{X}$ and $\mathrm{Y}$ directions and major principal stress of toppling dangerous rockmass considering $\mathrm{C} 1, \mathrm{C} 2$, $\mathrm{C} 3$. a) Displacement in $X$ direction (C1), b) Displacement in $Y$ direction (C1), c) Major principal stress (C1), d) Displacement in $X$ direction (C2), e) Displacement in Y direction (C2), f) Major principal stress (C2), g) Displacement in X direction (C3), h) Displacement in Y direction (C3), (i) Major principal stress (C3).

whereas the inner part has a contrary tendency. This means that the outer and inner rockmasses have different deformation tendencies: one is compressed and the other extended, which may cause the tensiling cracking of the fissure. Compared to the sliding type, the falling dangerous rockmass is influenced more obviously by the rainfall and seismic activity from the aspect of displacement variation. As to the analysis of major principal stress, the stress variation mainly occurred at the fissure tip and the lower part of jointed rock near the soft rock stratum. We can conclude that the expansion of vertical fissure and crack of the rock bridge are the main reasons causing
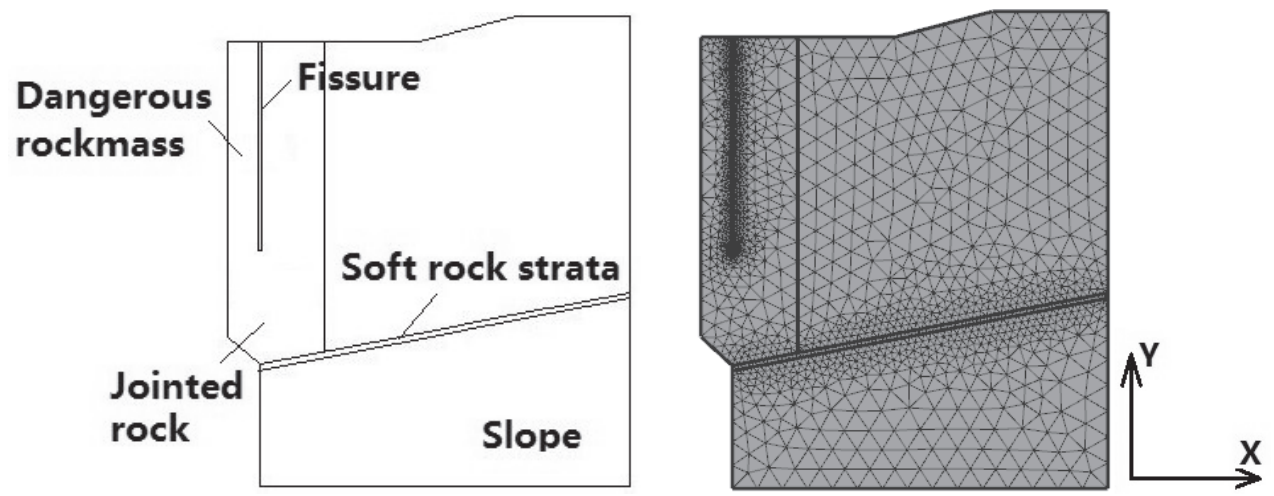

Fig. 7. Numerical model of falling dangerous rockmass. 
Table 3. Material parameters of the numerical model.

\begin{tabular}{|c|c|c|c|c|c|}
\hline & Elastic Modulus (GA) & $\begin{array}{c}\text { Poisson } \\
\text { ratio }\end{array}$ & $\begin{array}{c}\text { Cohesion } \\
(\mathrm{MPa})\end{array}$ & $\begin{array}{c}\text { Internal friction } \\
\text { angle }\left({ }^{\circ}\right)\end{array}$ & $\begin{array}{c}\text { Density } \\
\left(\mathrm{kg} / \mathrm{m}^{3}\right)\end{array}$ \\
\hline Slope & 23.98 & 0.2 & 2.5 & 53 & 2930 \\
\hline Jointed rock & 2.97 & 0.3 & 1 & 46 & 2900 \\
\hline Soft rock strata & 1.794 & 0.3 & 0.15 & 37 & 2840 \\
\hline
\end{tabular}

the falling of this dangerous rockmass, and the soft rock stratum is the inducement of the strength decrease of the rock bridge. If the rock bridge has a higher strength, it would come to the toppling failure mode as shown in the aforesaid numerical model.

Based on the numerical simulation of three dangerous rockmass types, the influences of rainfall and seismic activity on the stability of dangerous rockmass were investigated. The results show that rainfall and seismic activity play important roles in the stability of rockmass, and displacement and principal stress are affected by these two factors obviously, which reminds us that external factors should be considered in the stability analysis to avoid disasters. In the next section, a case study is performed referring to the conclusions from the numerical simulations.

\section{Stability Evaluation of Wangxia Dangerous Rockmass}

\section{General Setting}

The Wangxia dangerous rockmass in Wangxia village is located on the left bank of the Yangtze River in Wushan County in the Great Three Gorges area a)

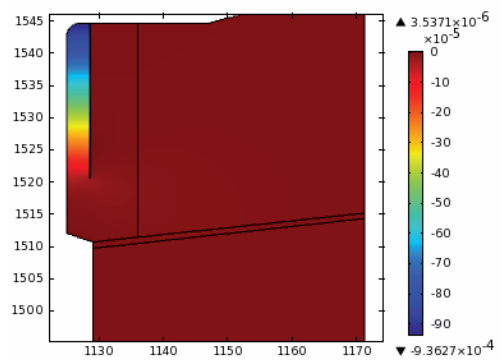

d)

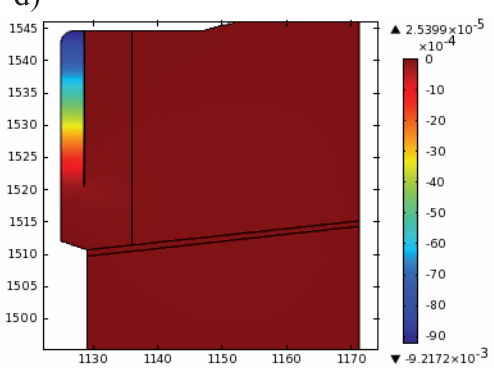

g)

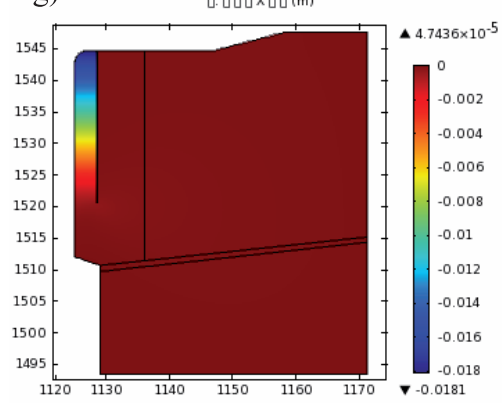

b)

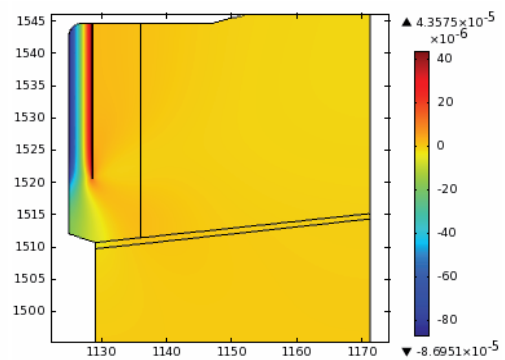

e)

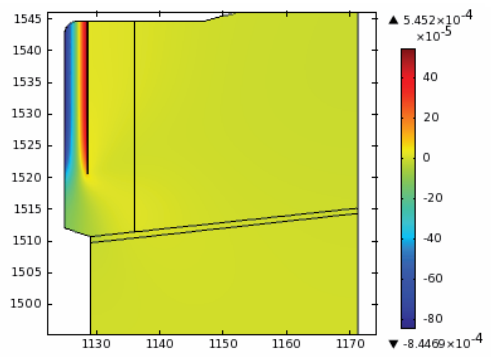

h)

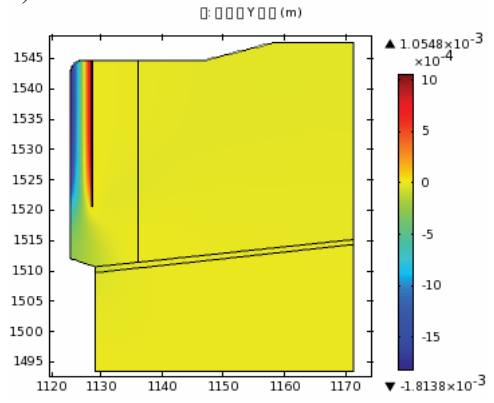

c)

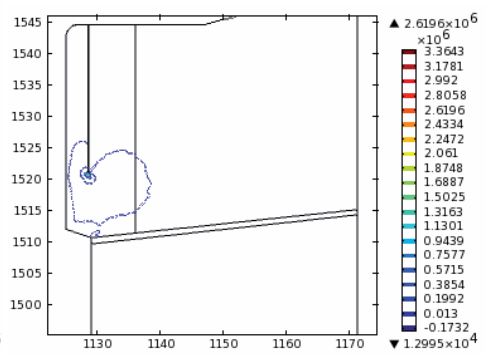

f)

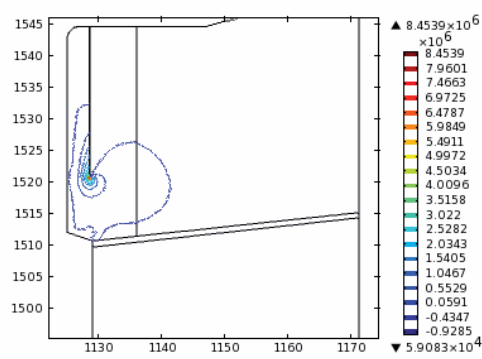

i)

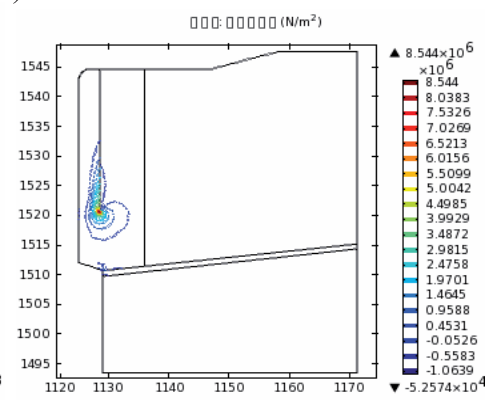

Fig. 8. Displacement in $\mathrm{X}$ and $\mathrm{Y}$ directions and major principal stress of falling dangerous rockmass considering $\mathrm{C} 1, \mathrm{C} 2, \mathrm{C}$. a) Displacement in $\mathrm{X}$ direction $(\mathrm{C} 1)$, b) Displacement in $\mathrm{Y}$ direction $(\mathrm{C} 1)$, c) Major principal stress (C1), d) Displacement in X direction (C2), e) Displacement in Y direction (C2), f) Major principal stress (C2), g) Displacement in X direction (C3), h) Displacement in Y direction (C3), i) Major principal stress (C3). 


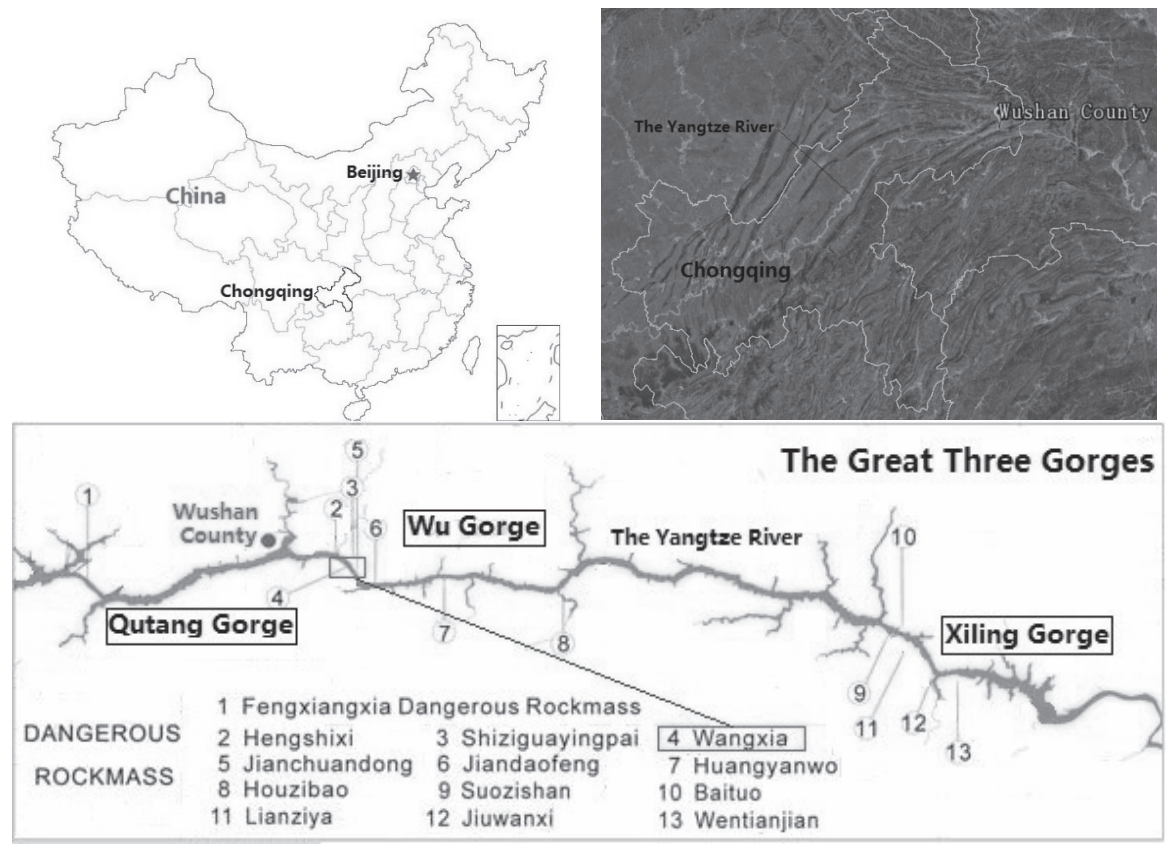

Fig. 9. Geographical position of the Wangxia dangerous rockmass [13].

of southwestern China (Fig. 9). The Great Three Gorges area has a subtropical monsoon climate that is warm and humid. The average annual rainfall is $1181.2 \mathrm{~mm}$, and rainfall is frequent from May to September. The largest monthly rainfall is $7411.8 \mathrm{~mm}$ and the largest daily rainfall is $175 \mathrm{~mm}$. The longest rainy period lasted for 16 days as recorded. The dangerous rockmass is in the core section of the Hengshixi anticline, where the stratum is flat with a formation of $340^{\circ} \angle 5^{\circ}$, the slope body is composed of Permian Gufeng Formation (Pg), Longtan
Formation (Plt) and Wujiaping Formation (Pw). The lithology of $\mathrm{Pg}$ is black lamina shale, lamina argillite, and lamina dolostone. Plt is grey thick shale, lamina sandstone with coal contained within, and the $\mathrm{Pw}$ is grey dark lamina silicon limestone and lamina shale. The flat section is composed of mainly shale, whereas the steep section is mainly composed of a mixed layer of argillite and limestone. The dangerous rockmass is located on a slope with an elevation of between $1100 \mathrm{~m}$ and $1250 \mathrm{~m}$, the slope root is a flat slope within its $30 \mathrm{~m}$,

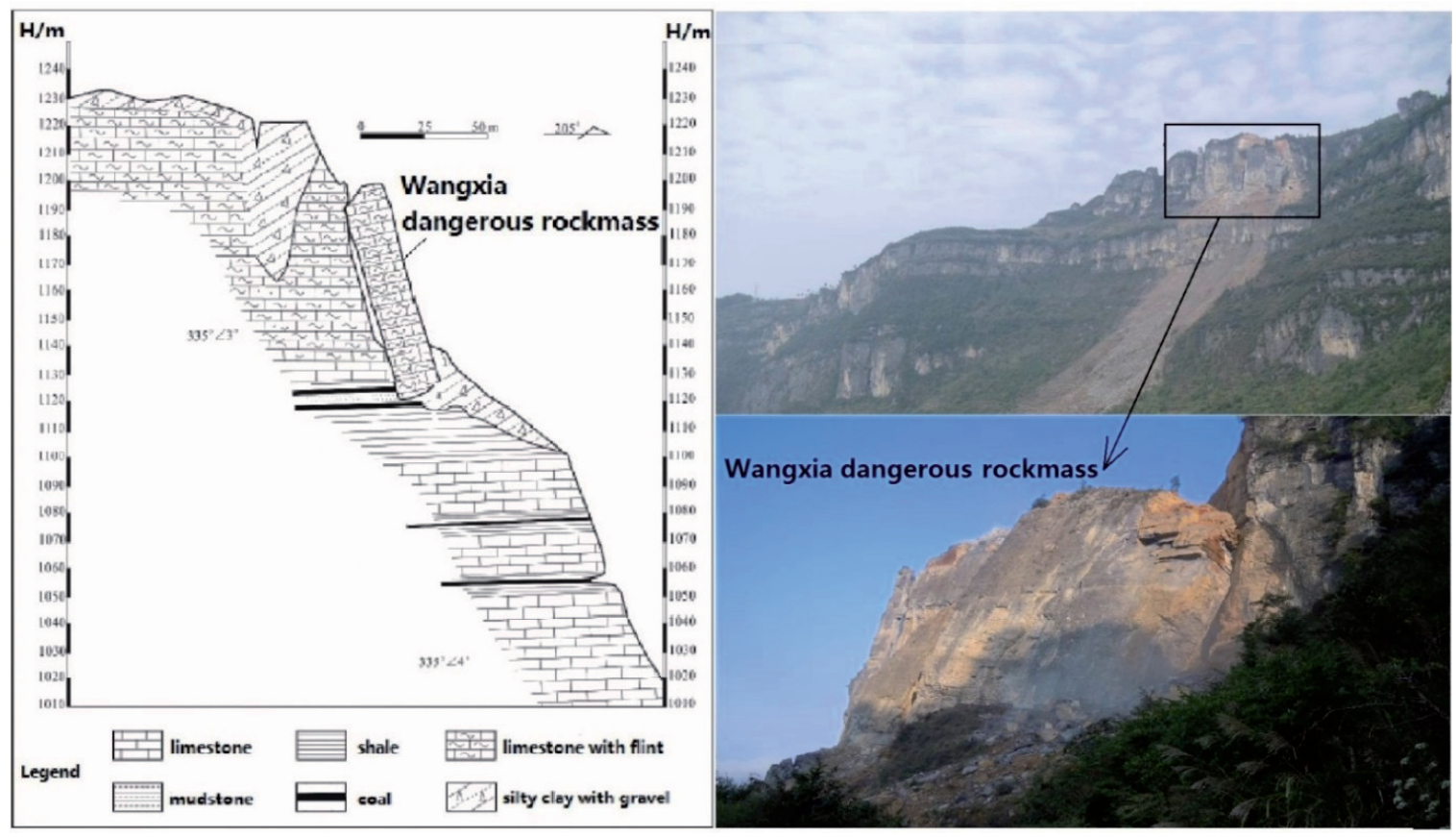

Fig. 10. Engineering geology profile and views of Wangxia dangerous rockmass (modified based on [12]). 

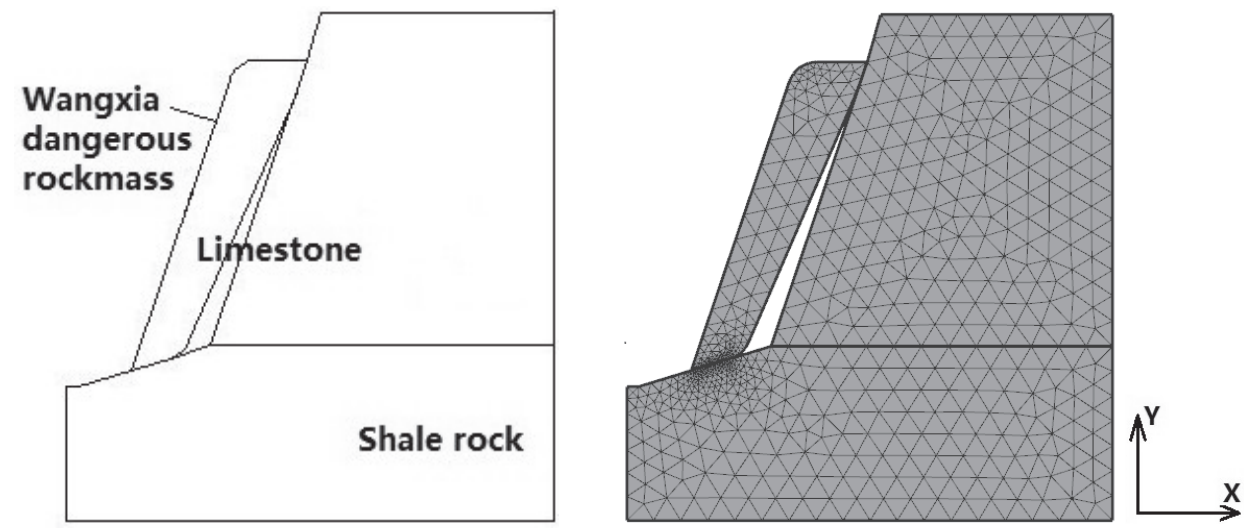

Fig. 11. Numerical model of Wangxia dangerous rockmass.

and the inclination at the root is $30^{\circ}$, whereas inclination at the top is almost $90^{\circ}$. There are six large fractures existing within the slope, and the Wangxia dangerous rockmass with the dimensions of $120 \mathrm{~m}$ long, 30 35 m wide, and $70 \mathrm{~m}$ high was formed. Its total volume is about $40 \times 10^{4} \mathrm{~m}^{3}$ [12-13], the engineering geology profile and views of Wangxia dangerous rockmass can be seen in Fig. 10. This dangerous rockmass constitutes a huge threat to local residents and traffic safety.

\section{Stability Analysis of Wangxia Dangerous Rockmass}

\section{Rockmass Model and Material Parameters}

The created model of Wangxia dangerous rockmass is $70 \mathrm{~m}$ high and $10 \sim 15 \mathrm{~m}$ wide. There is one penetrable fracture between the dangerous rockmass and slope. The rockmass relies on the slope base rock and this type belongs to the sliding dangerous rockmass. The numerical model is shown in Fig. 11. The slope material parameters were determined by mechanical tests in laboratory and are shown in Table 4 . The test processes are shown in Fig. 12.

\section{Numerical Analysis of Wangxia Dangerous Rockmass Stability}

The displacement in $\mathrm{X}$ and $\mathrm{Y}$ directions and the major principal stress of the numerical model considering combination $1,2,3(\mathrm{C} 1, \mathrm{C} 2, \mathrm{C} 3)$ were shown in Fig. 13 (a-f), and (g-i), respectively. In this simulation, the influences of gravity, heavy rain, and earthquake on the dangerous rock mass were taken into account. In view of the stress map, the dangerous rockmass is stable due to the reverse support provided by the bottom bedrock and the lateral support provided by slope. Thus, once the bottom bedrock softens, it would obviously cause damage to the entire dangerous rockmass. Therefore, the changes of physical and mechanical properties of the bedrock, both the rain state and the softening of the bedrock properties are of great significance to the analysis of the stability of dangerous rockmass. From the displacement diagram, we can see that the maximum horizontal displacement value of the dangerous rockmass is $1.7539 \mathrm{e}-3 \mathrm{~m}$ in the case of gravity only, and it reaches $1.7847 \mathrm{e}-3 \mathrm{~m}$ in the rainfall state, showing that heavy rainfall has great influence on the stability of Wangxia dangerous rockmass. In terms of the mechanism, it is mainly because of the softening of the bedrock. In the displacement diagrams, the maximum displacement happens in the bottom of the dangerous rockmass, which shows a downward trend. The tensile damage may occur in the middle of rockmass considering the self-gravity, and it should be taken into consideration seriously. In the case of seismic action, the earthquake is often ignored in the stability analysis of some dangerous rockmass due to the limit of occurance frequency. However, its influence on rockmass stability is undoubtedly the most important among the various factors. In the simulation, we can see that the horizontal displacement increases from $-1.7847 \mathrm{e}-3 \mathrm{~m}$ to $-1.9734 \mathrm{e}-3 \mathrm{~m}$ with the application of $0.05 \mathrm{~g}$ seismic load factor, and its growth rate is expected to be significant. Therefore, we can predict the failure mode and the mechanism of the dangerous rockmass by numerical simulation. The stability of the dangerous rockmass can be qualitatively

Table 4. Material parameters of the numerical model.

\begin{tabular}{|c|c|c|c|c|c|}
\hline & $\begin{array}{c}\text { Elastic Modulus } \\
(\mathrm{GA})\end{array}$ & $\begin{array}{c}\text { Poisson } \\
\text { ratio }\end{array}$ & $\begin{array}{c}\text { Cohesion } \\
(\mathrm{MPa})\end{array}$ & $\begin{array}{c}\text { Internal friction } \\
\text { angle }\left({ }^{\circ}\right)\end{array}$ & $\begin{array}{c}\text { Density } \\
\left(\mathrm{kg} / \mathrm{m}^{3}\right)\end{array}$ \\
\hline Limestone & 42 & 0.23 & 20 & 45 & 2680 \\
\hline Shale rock & 15 & 0.35 & 3 & 16.5 & 2620 \\
\hline
\end{tabular}




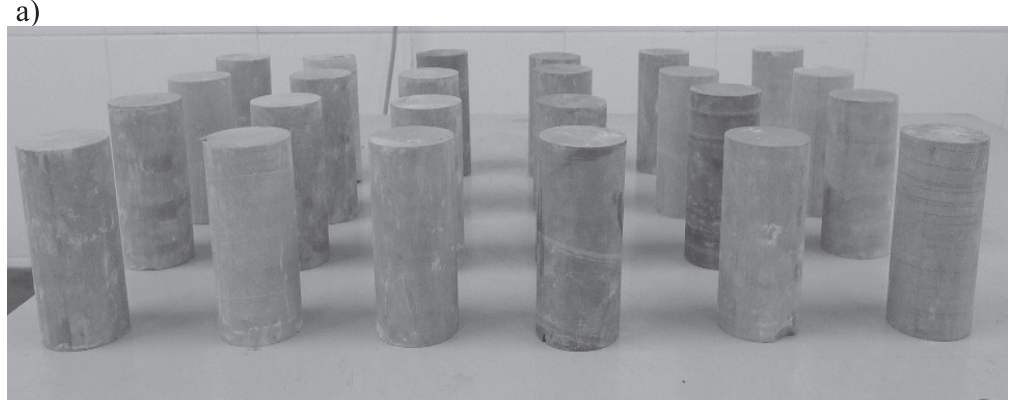

b)

c)
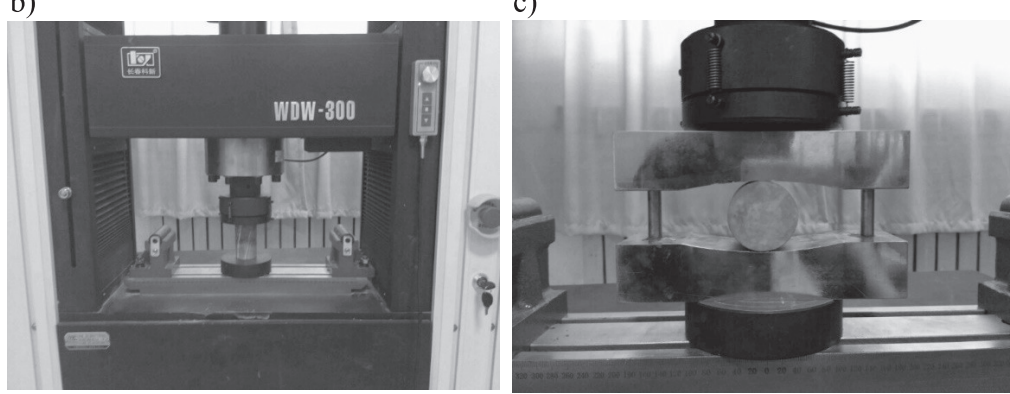

Fig. 12. Mechanical experiments on rock specimens. a) rock specimens acquired in situ, b) uniaxial compression test, c) brazil split test.

a)

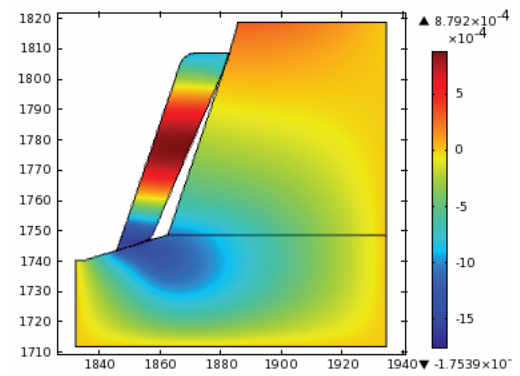

d)

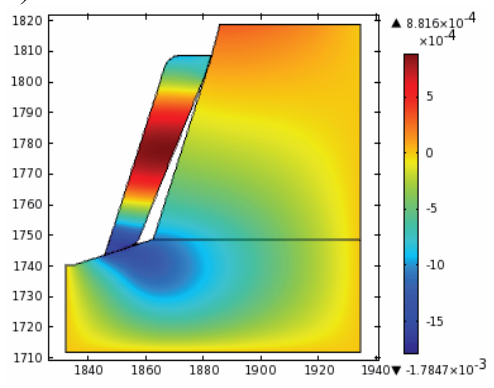

g)

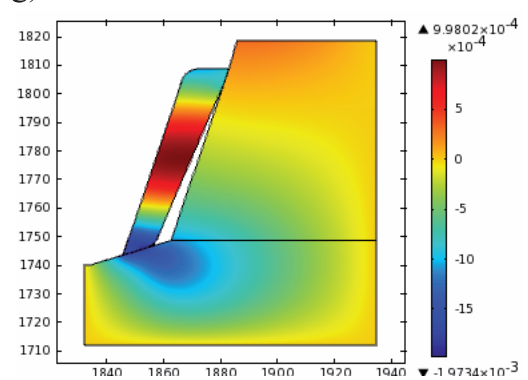

b)

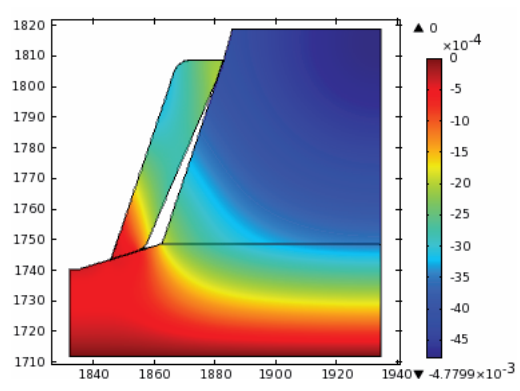

e)

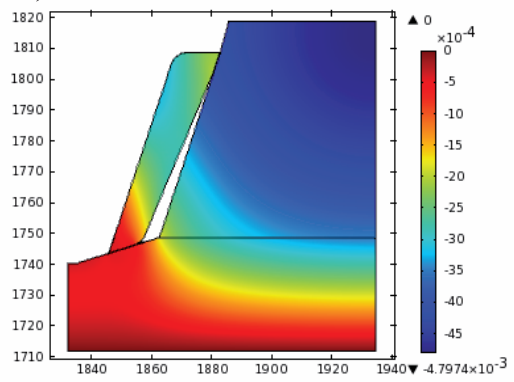

h)

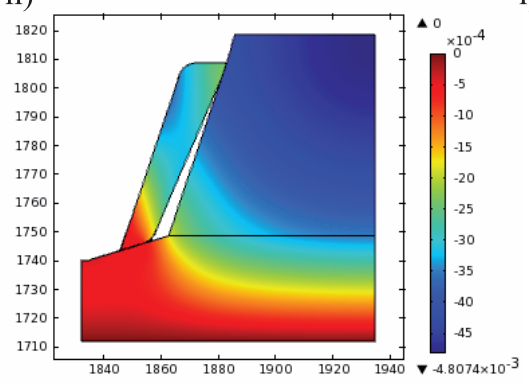

c)

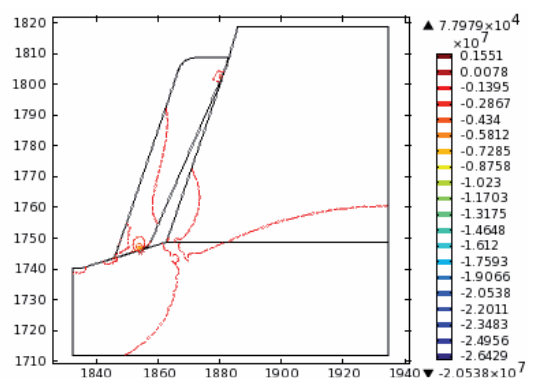

f)

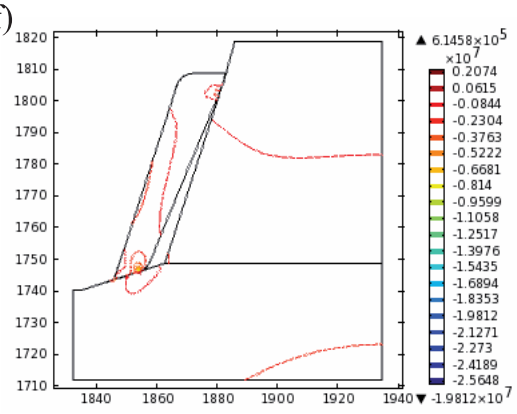

i)

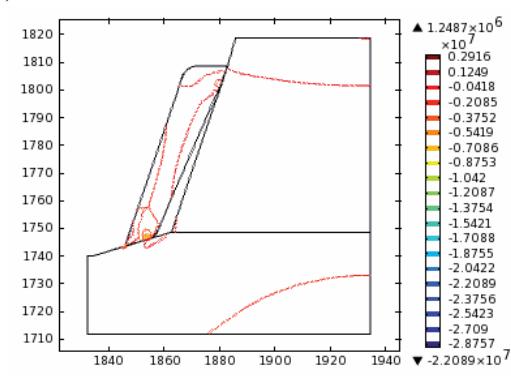

Fig. 13. Displacement in $\mathrm{X}$ and $\mathrm{Y}$ directions and major principal stress of Wangxia dangerous rockmass considering $\mathrm{C} 1, \mathrm{C} 2$, $\mathrm{C} 3$. a) Displacement in $\mathrm{X}$ direction (C1), b) Displacement in $\mathrm{Y}$ direction (C1), c) Major principal stress (C1), d) Displacement in $\mathrm{X}$ direction (C2), e) Displacement in Y direction (C2), f) Major principal stress (C2), g) Displacement in X direction (C3), h) Displacement in Y direction (C3), i) Major principal stress (C3). 


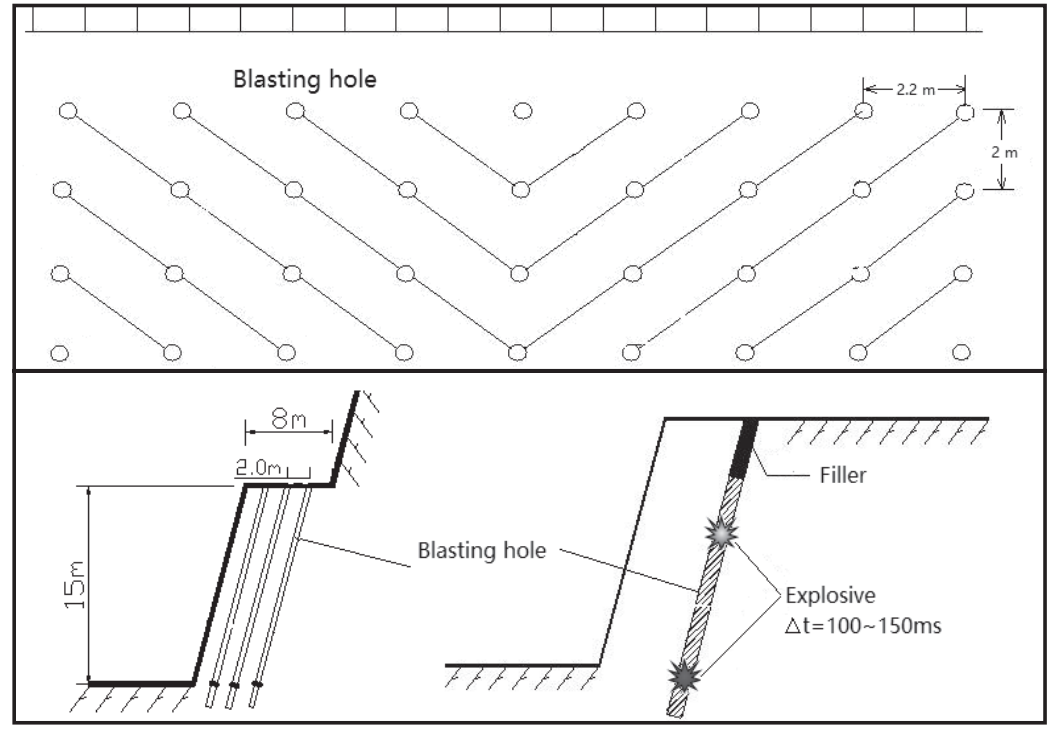

Fig. 14. Layout of blasting holes, the explosive holes adopted the multi-row and "V" type, the millisecond blasting technique was applied; the blasting time interval between two adjacent explosives was set as 100 150 ms.

analyzed, and the basis for the quantitative analysis of the stability of the dangerous rockmass stability can be provided.

\section{Static Calculation of Wangxia Dangerous Rockmass Stability}

The calculation of the dangerous rockmass is mainly based on the method provided by "Landslide Control Project Survey Specification" (DZ / T0218-2006) [11]. The calculation formula is as follows:

$$
F=\frac{(W \cos \alpha-V-Q \sin \alpha) \cdot \operatorname{tg} \phi+C L}{W \operatorname{Sin} \alpha+Q \cos \alpha}
$$

...where $V$ means fissure water pressure, $Q$ means seismic force, $F$ means stability coefficient of dangerous rockmass, $C$ means cohesion of fissure, $\phi$ means internal friction angle of fissure, $\alpha$ means incline angle of slide surface, $W$ means gravity of dangerous rockmass, and $L$ means length of fissure. Considering the three load combinations $(\mathrm{C} 1, \mathrm{C} 2, \mathrm{C} 3)$, the corresponding stability coefficients were calculated and the values are 1.10, 0.968 , and 0.951 , respectively. The calculation shows that the Wangxia dangerous rockmass is in a marginally stable state when considering self-gravity only and it would become unstable due to the influence of rainfall and seismic activity. Thus, there is a huge risk of collapse in the Wangxia dangerous rockmass.

\section{Treatment of Wangxia Dangerous Rockmass}

According to the stability analysis including geological investigation, numerical simulation and statics calculation, it is predicted that there is a huge possibility for the Wangxia dangerous rockmass to
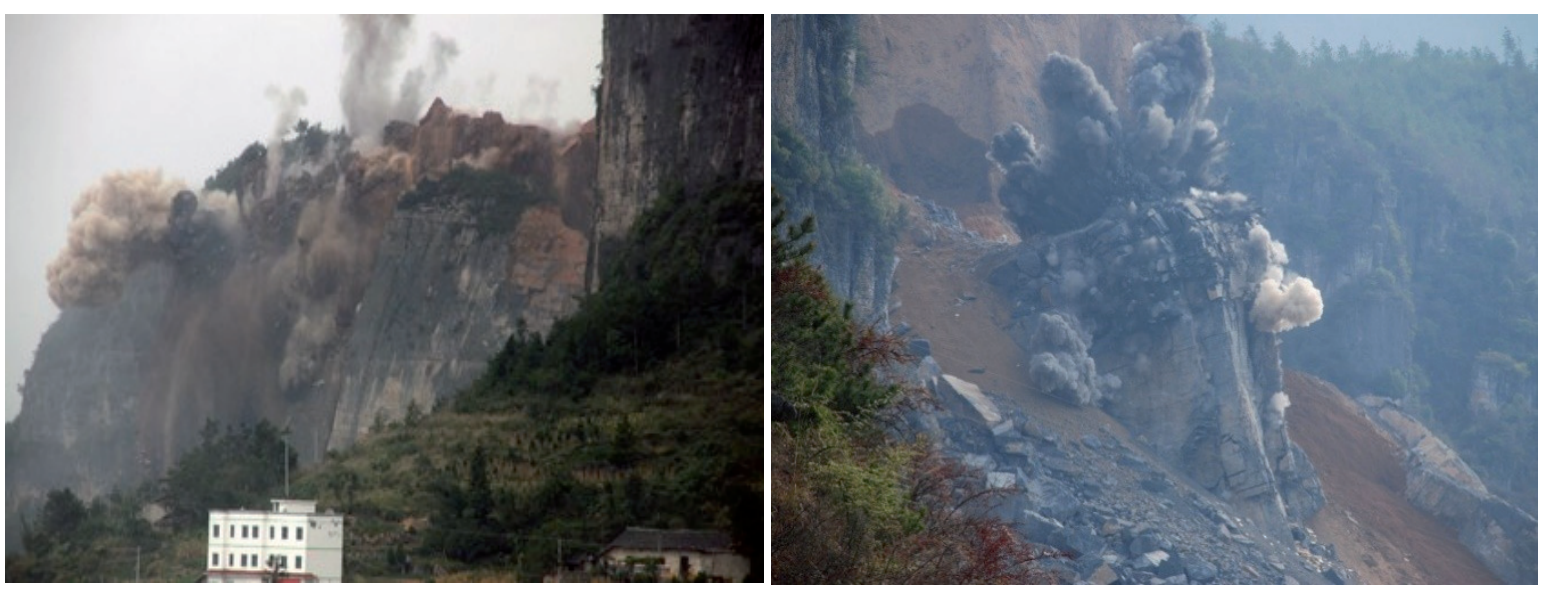

Fig. 15. Explosion of Wangxia dangerous rockmass. 
undergo a catastrophic collapse. To reduce the risk of such an event, a series of treatments were conducted, including blasting release of dangerous rockmass and a set of rockfall protection measures.

\section{Blasting of Wangxia Dangerous Rockmass}

In the blasting scheme, the deep hole and oneoff blasting was carried out. Firstly, the drilling rig was taken to drill the target hole, and the electronic detonators and explosives were connected and put in the deep hole. In order to ensure the stability of the rockmass after blasting, inclined drilling was conducted. Layout of explosive holes adopted the multi-row and "V" shape, the millisecond blasting technique was also applied.

a)

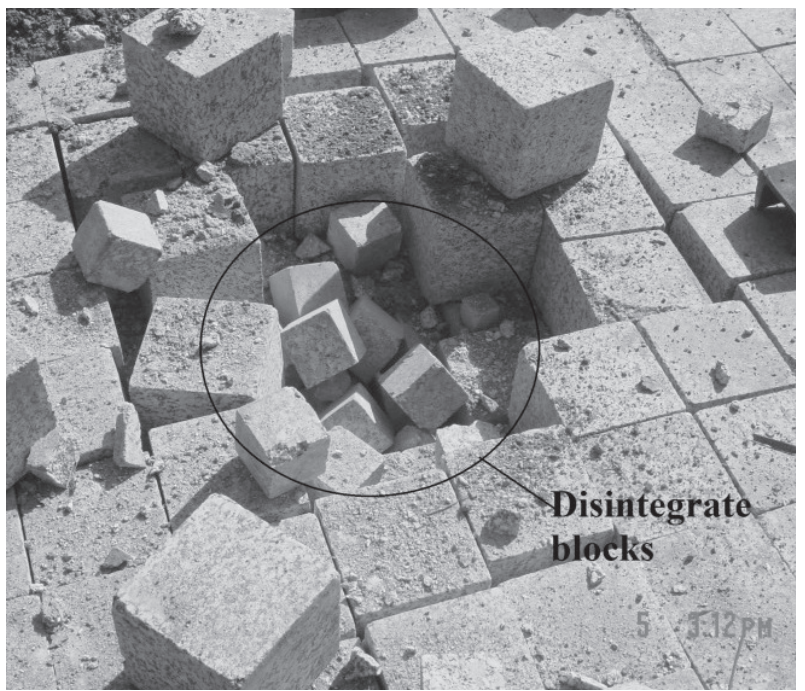

b)

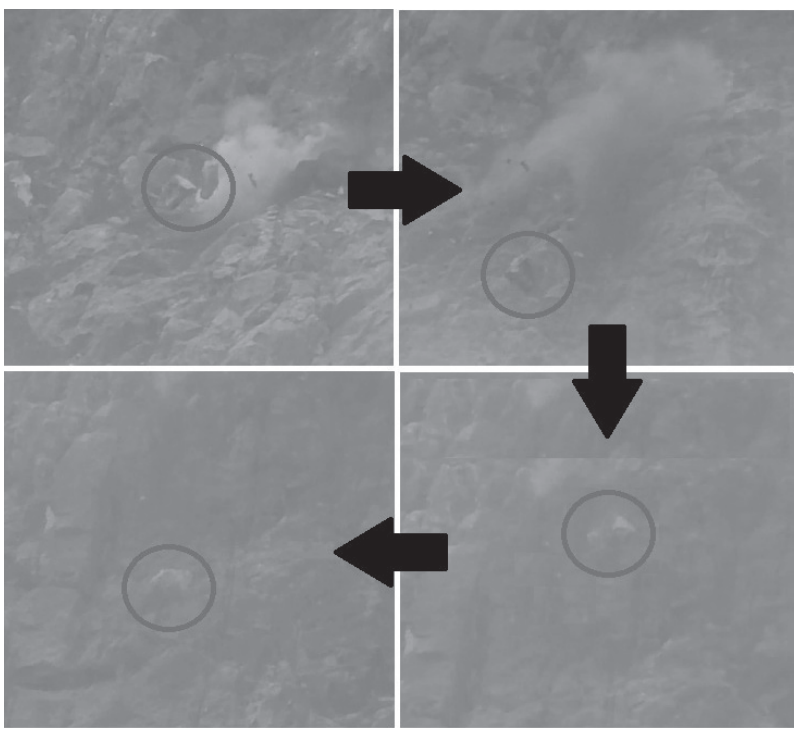

Fig. 16. Laboratory and field blasting tests were conducted to evaluate block weight and initial velocity: a) laboratory blasting test was conducted to measure average size of disintegrated blocks and b) field blasting test was conducted to measure the initial velocity based on rockfall trajectory.

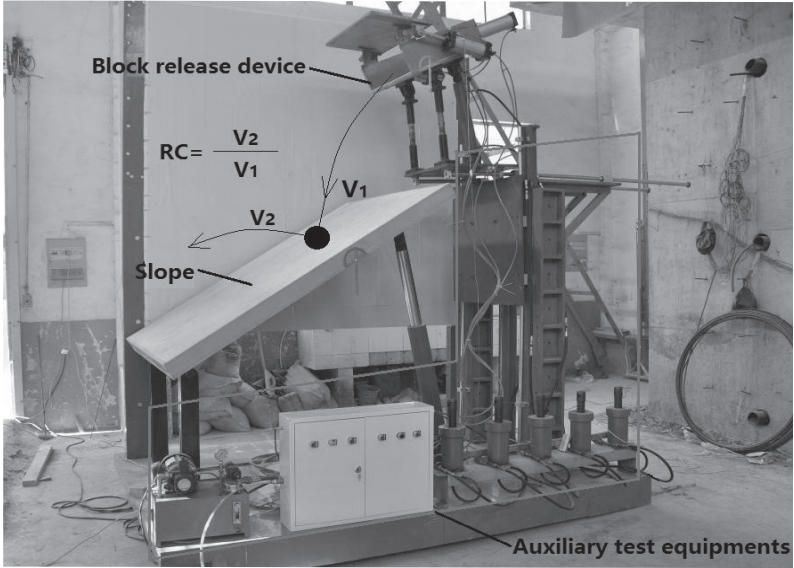

Fig. 17. Restitution coefficient (RC) test system (modified based on Li et al. [15]).

The blasting time interval between two adjacent explosives was set as 100 150 ms and it can significantly reduce the peak value of blasting stress and improve blasting efficiency. The layout of blasting holes is shown in Fig. 14 and the blasting process is shown in Fig. 15.

\section{Rockfall Protection Measures Against Rockmass Blasting}

To protect the downside village from being damaged by rockfall following the blasting of Wangxia's dangerous rockmass, an SNS flexible net was set on the slope under the dangerous rockmass before blasting. The size and location of the SNS net are important parameters related to protective efficiency. Thus, the rockfall trajectory prediction during rockmass blasting should be proposed. In this study, the simulation was carried out using the Rocscience Rocfall program [14], which presumes the rock block as a particle and expresses block rebound for the mass center of the block considering the characteristics of rockfall and slope in simulating the trajectory. In this software, the initial velocity, weight of falling block, and the restitution coefficient (RC) between block and slope during impact are the most important needed parameters [15]. As to the parameter evaluation of block weight and initial velocity, laboratory and field blasting tests were conducted. The average size of disintegrating blocks (Fig. 16a) was measured and the initial velocity was calculated

Table 5. Parameters used in the rockfall simulation.

\begin{tabular}{|c|c|}
\hline Parameter & Value \\
\hline Block weight & $10 \mathrm{~kg}$ \\
\hline Initial velocity & $20 \mathrm{~m} / \mathrm{s}$ \\
\hline Normal restitution coefficient & 0.25 \\
\hline Tangential restitution coefficient & 0.85 \\
\hline
\end{tabular}


a)

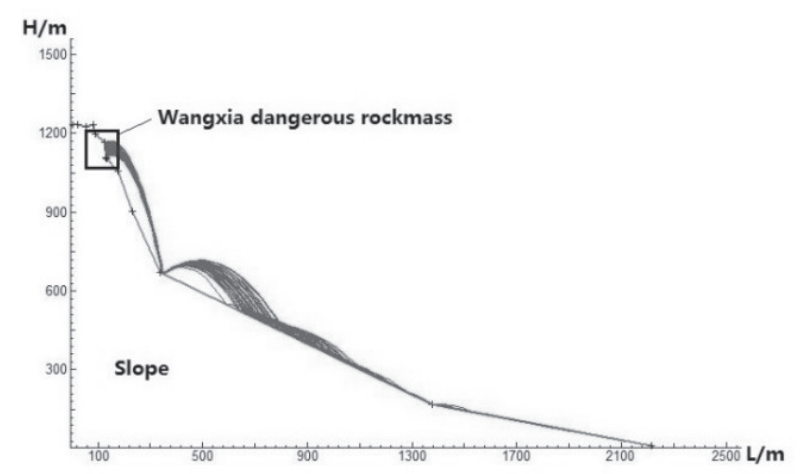

c) b)

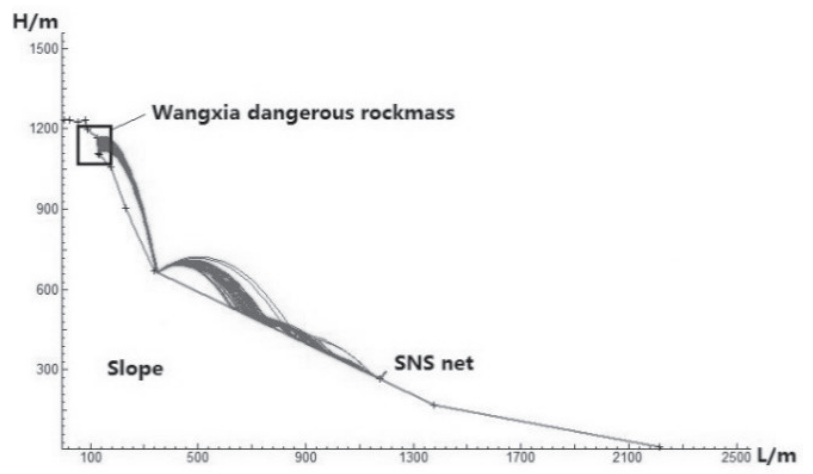

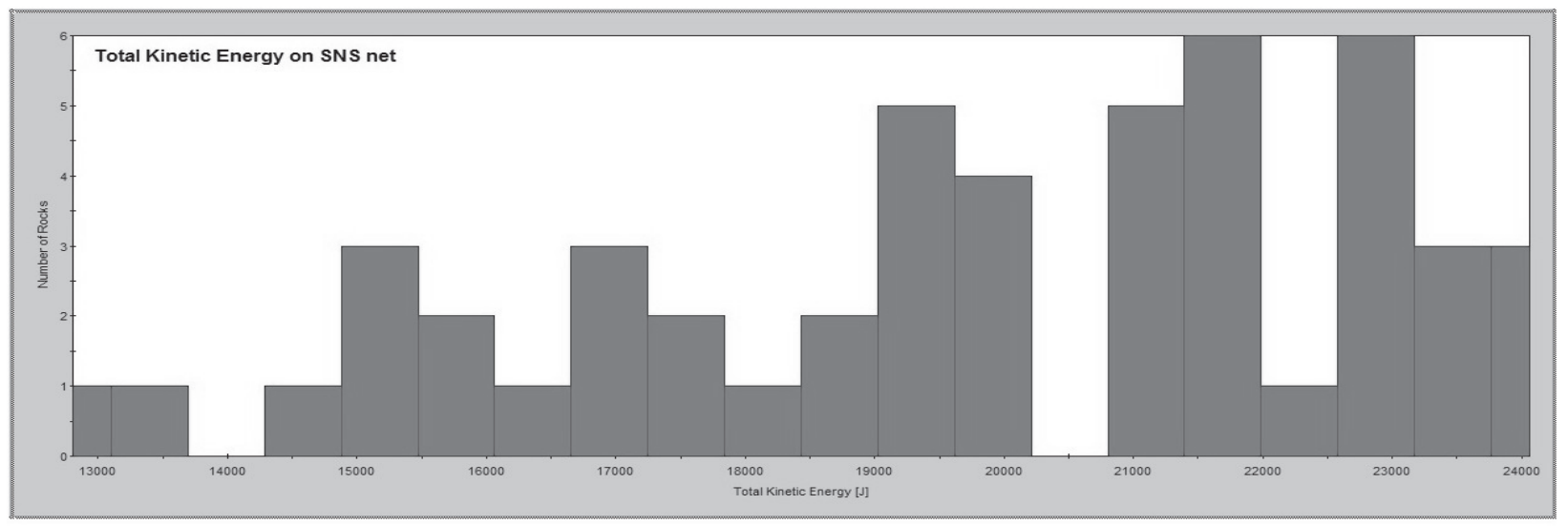

Fig. 18. Rockfall simulation and related dynamic parameters; a) Rockfall trajectory simulation without SNS net, b) Rockfall trajectory simulation with SNS net, c) Total kinetic energy of blocks on SNS net.

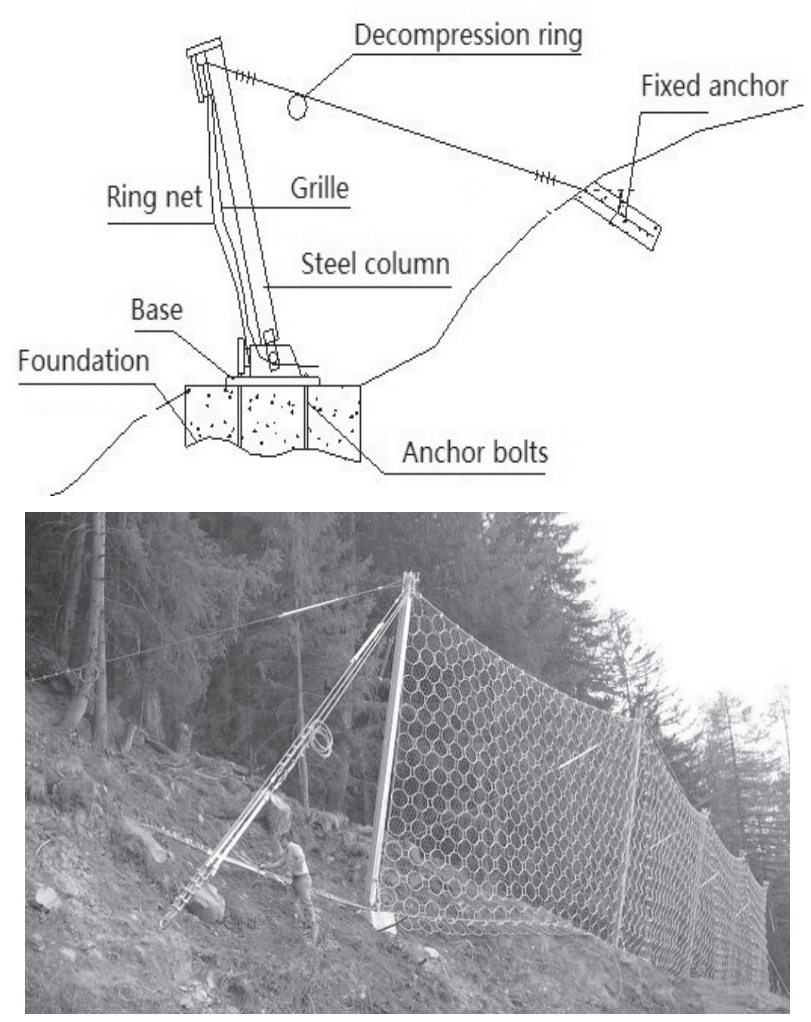

Fig. 19. The composition and installation of SNS net. based on the disintegrating block trajectory (Fig. 16b). The resulting regularity can provide a reference to the rockfall simulation for actual blasting of Wangxia's dangerous rockmass. As to the parameter evaluation of restitution coefficient during rockfall simulation, a model test was taken as shown in Fig. 17. The experiment result listed in $\mathrm{Li}$ et al. [15] reveals the variety law considering different conditions and provides a reference for the parameter evaluation. The parameters used in this rockfall simulation are listed in Table 5. The rockfall simulation results are shown in Fig. 18, and we can conclude from Fig. 18a) that the bounce height of falling blocks significantly decreased in the section from $900 \mathrm{~m}$ to $1100 \mathrm{~m}$ in height. Based on the trajectory predicted by the simulation, an SNS net with $5 \mathrm{~m}$ height was decided to be set at the location of $\mathrm{L}=1150 \mathrm{~m}$ and it was proven to be an efficient protective measure according to the rockfall trajectory simulation in Fig. 18b), the falling blocks were all intercepted by the SNS net. As is shown in Fig. 18c), the maximum kinetic energy of falling blocks only approach $25 \mathrm{~kJ}$, which is within the acceptable range of most SNS nets. The composition and installation of the SNS net are shown in Fig. 19. Finally, the engineering application proved that the SNS net design is efficient and there was no damage caused by rockfall. 


\section{Conclusions}

This article takes the Great Three Gorges area as a study object to analyze the stability of dangerous rockmass considering rainfall and seismic activity, and a series of viewpoints can be concluded as follows:

1) The dangerous rock masses are classified into three typical types, including sliding, falling, and topping. The classification basis was introduced and the instability model of the corresponding type was also proposed.

2) The stability of three typical dangerous rockmass types considering rainfall and seismic activity were simulated by numerical software. In the simulation, three load combinations were applied to the numerical models and the displacement and major principal stress images were given. The results show that rainfall and seismic activity play important roles in rockmass stability and the displacement and principal stress of the rockmass are obviously influenced. The fractures and fissures in the dangerous rockmass should be seriously considered for their easily expansive characteristics. Concluding from the simulation results, different types of dangerous rockmass have different plastic area distribution and initial damage zones when loads are applied.

3) The effect caused by rainfall on rockmass stability is significant in rainy seasons. On the one hand, high-intensity rainfall events would accelerate the weathering process, most of the weathered materials in the fissures are washed away and the rainwater flowing along the fissures weakens the strength and integrity of rockmass. On the other hand, the water gathered in the fissures may lead to a larger hydrostatic pressure that could promote the occurrence of collapse. The effect of seismic activity also cannot be ignored for its direct horizontal force applied on the dangerous rockmass. To analyze the stability of rock mass and specify corresponding treatments of potential dangerous rockmass, comprehensive factors should be taken into consideration.

4) The stability of Wangxia's dangerous rockmass was analyzed with geological investigation, numerical simulation, and static calculation methods. The results show that there is a huge risk that the dangerous rockmass would lose stability when rainfall season and seismic activity come. A blast was conducted to remove this dangerous rockmass and an SNS net design was proposed to intercept the distributed blocks based on rockfall trajectory simulation. The final engineering application proved the efficiency of the treatment and this case study can provide a significant reference for similar engineering projects in the future.

\section{List of Symbols}

$\mu$-horizontal seismic parameter

$P$ - horizontal earthquake force

$W$ - dangerous rockmass weight

$E$ - elastic modulus

$\rho$ - density

$\mathrm{g}$ - gravity

\section{List of Acronyms}

C combination

$\mathrm{RC}$ restitution coefficient

SNS soft net system

\section{Acknowledgements}

This work was supported by the National Natural Science Foundation of China (No. 51679131). The model tests were performed at the Geotechnical and Structural Engineering Research Center of Shandong University, and their help is highly appreciated.

\section{Conflict of Interest}

The authors declare no conflict of interest.

\section{References}

1. LI Z.Q., XUE Y.G., LI S.C., ZHANG L.W., WANG D., LI B. Deformation features and failure mechanism of steep rock slope under the mining activities and rainfall[J]. Journal of Mountain Science, 14 (1), 31, 2017.

2. CHEN D. Engineering geological problems in the three gorges project on the yangtze, china. Engineering Geology, 51 (3), 183, 1999.

3. SASAHARA K., SAKAI N. Development of shear deformation due to the increase of pore pressure in a sandy model slope during rainfall. Engineering Geology, 170, 43, 2014.

4. BUI H.H., FUKAGAWA R., SAKO K., WELLS J.C. Slope stability analysis and discontinuous slope failure simulation by elastoplastic smoothed particle hydrodynamics (SPH). Geotechnique 61 (7), 565, 2011.

5. LI L.C., TANG C.A., LI G., WANG S.Y. Numerical simulation of $3 \mathrm{~d}$ hydraulic fracturing based on an improved flow-stress-damage model and a parallel fem technique. Rock Mechanics and Rock Engineering, 45 (5), 801, 2012.

6. Lin P., Zhou W.Y., Liu H.Y. Experimental study on cracking, reinforcement and overall stability of the Xiaowan superhigh arch dam. Rock Mechanics and Rock Engineering, 48 (2), 819, 2015. 
7. ZHANG Q., LI S.C., LI L.P., ZHANG Q.Q., SHI S.S., WANG Q.H. Stability Analysis of Rock Mass with Sheet Slope Crack Based on Plates and Shells Theory. Polish Journal of Environmental Studies, 23 (4), 1297, 2014.

8. HUANG D., HUANG R.Q., PEI X.J., LIU W.H. Study on stability and reinforcement measures of an unstable rock masses of xiluodu hydropower station. Rock \& Soil Mechanics, 29 (5), 1425, 2008 [In Chinese].

9. DING Y., DANG C., YUAN G., WANG Q. Characteristics and remediation of a landslide complex triggered by the 2008 Wenchuan, China earthquake-case from Yingxiu near the earthquake epicenter. Environmental Earth Sciences, 67 (1), 161, 2012.

10. HUANG R.Q. Mechanism and geomechanical modes of landslide hazards triggered by Wenchuan 8.0 earthquake. Chinese Journal of Rock Mechanics and Engineering, 28 (6), 1239, 2009 [In Chinese].
11. CHEN H.K., TANG H.M., WANG R. Calculation method of stability for unstable rock and application to the three gorges reservoir, Chinese Journal of Rock Mechanics and Engineering, 23 (4), 614, 2004 [In Chinese].

12. GAO Y., LE Q., WANG H. Study on the key cracks deformation of Wangxia dangerous rock body in Wushan County. International Conference on Multimedia Technology (pp. 1250-1254). IEEE. 2011

13. WANG F., LI T. Landslide Disaster Mitigation in Three Gorges Reservoir, China, Environmental Science and Engineering, 30 (2), 184, 2009.

14. Rocscience, RocFall User's Manual, Toronto, Canada, 2004.

15. LI L.P., SUN S.Q., LI S.C., ZHANG Q.Q., HU C., SHI S.S Coefficient of Restitution and Kinetic Energy Loss of Rockfall Impacts. KSCE Journal of Civil Engineering, 20 (6), 2297, 2016. 
